\title{
Forehead or ear temperature measurement cannot replace rectal measurements, except for screening purposes
}

\author{
Christian Backer Mogensen ${ }^{1 *} \mathbb{D}$, Lena Wittenhoff², Gitte Fruerhøj ${ }^{2}$ and Stephen Hansen²
}

\begin{abstract}
Background: Measuring rectal temperature in children is the gold standard, but ear or forehead measures are less traumatic and faster. The quality of non-invasive devices has improved but concerns remain whether they are reliable enough to substitute rectal thermometers.

The aim was to evaluate in a real-life children population whether the forehead or ear temperature measurements could be used in screening to detect fever and if the agreement with the rectal temperature for different age groups is acceptable for clinical use.

Methods: Cross-sectional clinical study comparing temporal and tympanic temperatures to rectal temperature in 0-18-year-old children. The ear thermometer was a Pro 4000 Thermoscan, the temporal Exergen TAT. Rectal temperature $\geq 38.0^{\circ} \mathrm{C}$ was defined as fever.

Results: Among 995 children, 39\% had a fever. The ear thermometer had a significantly greater ability to detect fever than the temporal thermometer (AUC 0.972; 95\% Cl: 0.963-0.981 versus AUC 0.931; 95\% Cl: 0.915-0.947, $p<0$. 0001). Both devices had the lowest sensitivity in the youngest and oldest children, and only the ear thermometer reached a sensitivity above $90 \%$ in the $0.5-5$-year age group. The Bland-Altman analysis showed that the $95 \%$ limits of agreement for the temporal thermometer was between -1.2 to $+1.5^{\circ} \mathrm{C}$ and for the ear thermometer between -0.97 to $+1.07^{\circ} \mathrm{C}$.

Conclusions: Based on a large sample of children, the temporal measurement of temperature is not currently recommendable, but with the technology used in this study the ear measurement proved useful for screening purposes, especially among children aged 6 months to 5 years. For the exact measurement of temperature, the rectal method is still recommended.
\end{abstract}

Keywords: Pediatric, Temperature measurement, Ear temperature, Tympanic temperature, Rectal temperature, Temporal temperature, Emergency care

\section{Background}

Measuring the temperature in children with acute conditions is essential. Rectal measurement is the gold standard, [1] but there are alternatives. Using the ear or forehead temperature is less traumatic and allows a faster triage. A recent meta-analysis based on 75 studies concluded, that high quality data were limited and peripheral thermometers did not have clinically acceptable

\footnotetext{
* Correspondence: Christian.Backer.Mogensen@rsyd.dk

${ }^{1}$ University of Southern Denmark, Institute for Regional Health Research,

Kresten Philipsensvej 15, 6200 Aabenraa, Denmark

Full list of author information is available at the end of the article
}

accuracy to be recommended for clinical use. Among these studies $53 \%$ were more than 10 years old [2].

However, the quality of these devices for rapid, noninvasive temperature measurements has improved in recent years and suggestions have been made to replace rectal thermometers with these alternatives for children or to use the devices as screening instruments for fever $[1,3]$. A range of studies support this suggestion [4-7]. Since these studies have limitations in size or methodology, however, concerns have been raised as to whether the new devices are reliable enough to substitute for the 
rectal thermometer and if this reliability is consistent within different age groups [8].

The aim of the present study was, in a real-life population of children, acutely referred to a pediatric department; firstly, to evaluate, based on current technology, whether forehead or ear temperature measurements could be used as a screening tool to detect fever; and, secondly, to evaluate how well these measurements agrees with the rectal temperature within different age groups of children.

\section{Methods}

We performed a cross-sectional clinical study, comparing the temporal and tympanic temperatures to the rectal temperature in $0-18$-year-old children in real-life assessments. Children who were referred for any acute condition by the general practitioner to the pediatric emergency department of the hospital of Southern Jutland were included if oral parental consent was obtained and time allowed. We did not include children who were admitted directly to the neonatal ward, who had anal atresia or deformities of the outer ear. The three temperature measurements were performed immediately after each other by the same nurse in the following order: temporal, tympanic, and rectal measurement. The temperatures were recorded immediately by the nurse to pre-printed files together with information about gender and age in months. The new generation of tympanic thermometers measures the temperature over a wider angle and uses multiple measuring points, compared to former devices. We chose a Braun Welch Allyn Pro 4000 Thermoscan, released in 2006, where a heating element in the sensor warms the probe tip to just under normal body temperature to avoid cooling the ear canal [9]. The temporal thermometer was an infrared non-invasive Exergen TAT from GE Healthcare. The probe of the device is gently positioned on the center of the forehead and lightly slid across the forehead, keeping the sensor in contact with the skin until the hairline is reached while the temporal artery temperature is measured. The rectal thermometer was an OMRON Healthcare, maximum thermometer. All of the thermometers were purchased in 2010 for this study only. All of the nurses in the pediatric department were instructed in the correct use of the three devices. Compliance with the instructions was intermittently verified by the study nurse.

The results were intended to be analyzed as a total population and in six different age groups. We aimed at a sample size for analysis of minimum 99 children within each of the six age groups to be able to detect a minimum mean difference of $+/-0.3{ }^{\circ} \mathrm{C}$ with a standard deviation of $0.65{ }^{\circ} \mathrm{C}$ between the rectal and the alternative measurement, a $90 \%$ power, and a significance level of 0.05 , assuming normal distribution of the temperatures. The obtained data were normal distributed and the standard deviation around $1{ }^{\circ} \mathrm{C}$. Further details are reported in Additional file 1.

The recorded results were transferred to and analyzed in Stata 14. The rectal measurement was the reference temperature. A temperature of $\geq 38.0{ }^{\circ} \mathrm{C}$ was defined as fever. The ability to be used as a screening tool was evaluated by calculating the sensitivity, specificity, predictive values, and correct classification with a 95\% confidence interval (CI). We also calculated the area under the curve (AUC) in a receiver-operator characteristic (ROC) diagram, with a threshold for classification boundary of fever to $38.0{ }^{\circ} \mathrm{C}$ rectally. Since a device used for screening for fever should have a high sensitivity in order not to classify a febrile patient as not febrile, we sought a cut point for the examined devices where $95 \%$ of all children with rectal temperature $\geq 38.0{ }^{\circ} \mathrm{C}$ would be detected.

The agreement of the non-rectal thermometers with the rectal temperature was examined in a Bland-Altman analysis and plots to determine the level of agreement and the $95 \%$ limits of agreement.

The rectal temperature was the standard temperature measurement used for all children in the department, but was supplied by an initial ear- or temporal measurement as a screening for fever on arrival. The study was considered a quality assurance study of already implemented routines and no ethical clearance was required. Oral consent was obtained from the parents before the temperature measurements were performed. All of the data was anonymously recorded and the Danish Data Protection Agency confirmed that registration of the database was unnecessary.

\section{Results}

During the period under study, from December 2010 to November 2011, 2523 children were referred to the pediatric department. Among these children, 996 parents were asked to allow their child to participate, all of whom consented. Due to technical problems, the thermometers were unable to measure the temperature in 30 forehead measurements and 1 rectal temperature measurement, which left 995 children with a reference temperature and at least one other measurement for further analysis.

The median age of the children was 24 months (Inter Quartile Range 11-70 months) with 489 (49\%) girls, and the rectal temperatures indicated that $39 \%$ of the children had a fever.

Table 1 shows the screening measures for the detection of fever using the temporal or tympanic thermometer. For the whole population, the tympanic 
Table 1 Temporal and tympanic measurements of temperature as a screening tool for fever $\left(>=38.0^{\circ} \mathrm{C}\right)$

\begin{tabular}{|c|c|c|c|c|c|c|c|c|c|c|c|c|c|c|}
\hline \multirow[b]{2}{*}{ Age group } & \multirow[b]{2}{*}{ Method } & \multirow[b]{2}{*}{$\begin{array}{l}\text { No. of } \\
\text { children }\end{array}$} & \multicolumn{10}{|c|}{ Screening measures (in \%) } & \multirow[b]{2}{*}{ AUC } & \multirow[b]{2}{*}{$95 \% \mathrm{Cl}$} \\
\hline & & & Sensitivity & $95 \% \mathrm{Cl}$ & Specificity & $95 \% \mathrm{Cl}$ & $\begin{array}{l}\text { Positive } \\
\text { predictive } \\
\text { value }\end{array}$ & $95 \% \mathrm{Cl}$ & $\begin{array}{l}\text { Negative } \\
\text { predictive } \\
\text { value }\end{array}$ & $95 \% \mathrm{Cl}$ & $\begin{array}{l}\text { Correctly } \\
\text { classified }\end{array}$ & $95 \% \mathrm{Cl}$ & & \\
\hline \multirow[t]{2}{*}{ Total } & Temporal & 965 & 81 & $77-85$ & 90 & $87-92$ & 84 & $80-88$ & 88 & $86-91$ & 87 & $84-89$ & 0.931 & $0.915-0.947$ \\
\hline & Tympanic & 995 & 89 & $86-92$ & 94 & $92-96$ & 91 & $87-93$ & 93 & $91-95$ & 92 & $90-94$ & 0.972 & $0.963-0.981$ \\
\hline \multirow[t]{2}{*}{ 0-5 months } & Temporal & 133 & 75 & $53-90$ & 93 & $86-97$ & 69 & $48-86$ & 94 & $88-98$ & 89 & 83-94 & 0.924 & $0.875-0.973$ \\
\hline & Tympanic & 136 & 67 & $45-84$ & 96 & $91-99$ & 80 & $56-94$ & 93 & $87-97$ & 91 & $85-95$ & 0.936 & $0.875-0.996$ \\
\hline \multirow[t]{2}{*}{ 6-11 months } & Temporal & 124 & 80 & $67-89$ & 91 & $82-97$ & 88 & 75-95 & 85 & $75-92$ & 86 & 79-92 & 0.943 & $0.905-0.980$ \\
\hline & Tympanic & 128 & 93 & $82-98$ & 96 & $89-99$ & 94 & 84-99 & 95 & $87-99$ & 95 & $89-98$ & 0.984 & $0.964-1.000$ \\
\hline \multirow[t]{2}{*}{ 12-35 months } & Temporal & 311 & 82 & $75-88$ & 87 & $81-92$ & 87 & $81-92$ & 82 & $75-88$ & 85 & $80-88$ & 0.919 & 0.889-0.949 \\
\hline & Tympanic & 320 & 92 & $86-95$ & 93 & $88-96$ & 93 & $88-97$ & 91 & $86-95$ & 91 & $89-95$ & 0.969 & $0.951-0.987$ \\
\hline \multirow[t]{2}{*}{ 3-5 years } & Temporal & 162 & 92 & 83-97 & 88 & $79-94$ & 86 & 76-93 & 93 & $85-97$ & 90 & $85-94$ & 0.961 & $0.934-0.986$ \\
\hline & Tympanic & 169 & 92 & $84-97$ & 90 & $82-96$ & 89 & 80-95 & 93 & $86-98$ & 91 & $86-95$ & 0.981 & $0.964-0.997$ \\
\hline \multirow[t]{2}{*}{ 6-11 years } & Temporal & 131 & 72 & $56-85$ & 91 & $83-96$ & 80 & $64-91$ & 87 & $78-93$ & 85 & $77-90$ & 0.900 & $0.842-0.958$ \\
\hline & Tympanic & 135 & 87 & 74-95 & 92 & 85-97 & 85 & $72-94$ & 93 & $86-98$ & 90 & $84-95$ & 0.968 & $0.943-0.993$ \\
\hline \multirow[t]{2}{*}{$12-18$ years } & Temporal & 104 & 74 & $52-90$ & 93 & $85-97$ & 74 & $52-90$ & 93 & $85-97$ & 88 & 80-94 & 0.932 & $0.878-0.986$ \\
\hline & Tympanic & 107 & 84 & $64-96$ & 98 & $92-100$ & 91 & $72-99$ & 95 & 88-99 & 94 & $88-98$ & 0.963 & $0.925-1.000$ \\
\hline
\end{tabular}

Cl confidence interval, AUC area under receiver-operating characteristics curve

thermometer had a significantly greater ability to detect fever than the temporal thermometer (AUC 0.972; 95\% CI: $0.963-0.981$ versus AUC 0.931; 95\% CI: 0.915-0.947, $p<0.0001)$, Fig. 1. The temporal thermometer had a sensitivity ranging from 72 to $92 \%$, while the tympanic thermometer ranged from 67 to $93 \%$ in sensitivity in the different age groups. Both devices had the lowest sensitivity in the youngest and oldest children, and only the tympanic thermometer reached a sensitivity above $90 \%$ in the group of children aged 6 months to 5 years. Using a cut point of $37.4{ }^{\circ} \mathrm{C}$ for the temporal measurements, which $66 \%$ of all children fulfilled, resulted in a sensitivity for fever of $>95 \%$ and a positive predictive value of $57 \%$. For the tympanic measurements the cut point for $95 \%$ sensitivity was $37.8{ }^{\circ} \mathrm{C}$, which $44 \%$

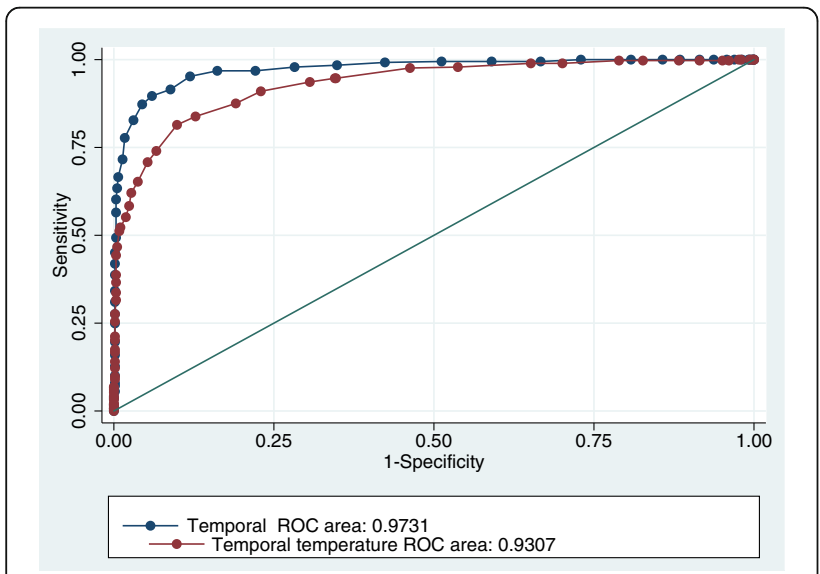

Fig. 1 Temporal and tympanic measurements for fever $\geq 38^{\circ} \mathrm{C}$ of the children fulfilled with a positive predictive value of $83 \%$.

Table 2 reports the mean temperatures and the Bland-Altman comparison in the age groups measured by the different devices.

The mean difference from the temporal to the rectal temperature was small but significant: $0.13{ }^{\circ} \mathrm{C}(95 \% \mathrm{CI}$ $\left.0.08-0.17{ }^{\circ} \mathrm{C}, p<0.0001\right)$. In the different age groups, the mean difference ranged from -0.04 to $0.25{ }^{\circ} \mathrm{C}$. The 95\% limits of agreement for the temporal thermometer was between -1.2 to $+1.5{ }^{\circ} \mathrm{C}$, and the same variation was seen within the different age groups. Figure 2 indicates a systematic difference for higher temporal temperatures.

The mean difference from the tympanic to the rectal temperature was $0.05{ }^{\circ} \mathrm{C}\left(95 \% \mathrm{CI} 0.02-0.08{ }^{\circ} \mathrm{C}\right.$, p: 0.004$)$, and varied between $-0.14{ }^{\circ} \mathrm{C}$ to $0.19{ }^{\circ} \mathrm{C}$ in the age groups. The $95 \%$ limits of agreement for the tympanic thermometer was between -0.97 to $+1.07{ }^{\circ} \mathrm{C}$ for the whole group and almost the same interval within the different age groups. Figure 3 does not indicate any systematic differences.

\section{Discussion}

We found, that as a screening tool to detect fever $\geq 38.0{ }^{\circ} \mathrm{C}$, the tympanic thermometer was significantly better than the temporal thermometer. However, the 6 months to 5 years age group was the only one in which the sensitivity of the ear thermometer was above $90 \%$. If the tympanic device was used as a screening tool for fever and the tympanic measurement $\geq 37.8{ }^{\circ} \mathrm{C}$ was regarded as a positive test of fever, this meant that more than $95 \%$ of all febrile children 
Table $\mathbf{2}$ Temperature variation within the age groups

\begin{tabular}{|c|c|c|c|c|c|c|c|}
\hline \multirow[b]{2}{*}{ Age group } & \multirow[b]{2}{*}{ No. of children } & \multirow[b]{2}{*}{ Method } & \multirow[b]{2}{*}{ Mean temperature $\left({ }^{\circ} \mathrm{C}\right)$} & \multirow[b]{2}{*}{$95 \% \mathrm{Cl}$} & \multicolumn{3}{|c|}{ Bland-Altman comparison $\left({ }^{\circ} \mathrm{C}\right)$} \\
\hline & & & & & Mean difference & $95 \% \mathrm{Cl}$ & 95\% prediction interval \\
\hline \multirow[t]{3}{*}{ Total } & 965 & Temporal & 37.9 & $37.9-38.0$ & 0.13 & $0.08-0.17$ & $-1.20-1.49$ \\
\hline & 995 & Tympanic & 37.8 & $37.8-37.9$ & 0.05 & $0.02-0.08$ & $-0.97-1.07$ \\
\hline & 995 & Rectal & 37.8 & $37.7-37.9$ & reference & & \\
\hline \multirow[t]{3}{*}{$0-5$ months } & 133 & Temporal & 37.5 & $37.4-37.7$ & 0.16 & $0.06-0.25$ & $-0.97-1.29$ \\
\hline & 136 & Tympanic & 37.1 & $37.1-37.3$ & -0.14 & $-0.23--0.06$ & $-1.15-0.87$ \\
\hline & 136 & Rectal & 37.4 & $37.2-37.5$ & reference & & \\
\hline \multirow[t]{3}{*}{ 6-11 months } & 124 & Temporal & 37.9 & $37.7-38.1$ & -0.04 & $-0.16-0.09$ & $-1.43-1.36$ \\
\hline & 128 & Tympanic & 38.0 & $37.8-38.1$ & 0.00 & $-0.08-0.08$ & $-0.89-0.90$ \\
\hline & 128 & Rectal & 38.0 & $37.8-38.1$ & reference & & \\
\hline \multirow[t]{3}{*}{ 12-35 months } & 311 & Temporal & 38.1 & $38.0-38.3$ & 0.06 & $-0.02-0.14$ & $-1.35-1.46$ \\
\hline & 320 & Tympanic & 38.1 & $38.0-38.2$ & 0.01 & $-0.04-0.07$ & $-1.01-1.02$ \\
\hline & 320 & Rectal & 38.1 & $37.9-38.2$ & reference & & \\
\hline \multirow[t]{3}{*}{ 3-5 years } & 162 & Temporal & 38.2 & $38.0-38.3$ & 0.25 & $0.16-0.35$ & $0.96-1.47$ \\
\hline & 169 & Tympanic & 38.1 & $37.9-38.3$ & 0.19 & $0.12-0.26$ & $-0.73-1.11$ \\
\hline & 169 & Rectal & 37.9 & $37.7-38.1$ & reference & & \\
\hline \multirow[t]{3}{*}{$6-11$ years } & 131 & Temporal & 37.8 & $37.7-38.0$ & 0.21 & $0.10-0.32$ & $-1.06-1.49$ \\
\hline & 135 & Tympanic & 37.8 & $37.6-38.0$ & 0.18 & $0.09-0.27$ & $-0.85-1.21$ \\
\hline & 135 & Rectal & 37.6 & $37.5-37.8$ & reference & & \\
\hline \multirow[t]{3}{*}{$12-18$ years } & 104 & Temporal & 37.6 & $37.4-37.8$ & 0.17 & $0.04-0.30$ & $-1.18-1.52$ \\
\hline & 107 & Tympanic & 37.5 & $37.3-37.7$ & 0.05 & $-0.06-0.16$ & $-1.07-1.17$ \\
\hline & 107 & Rectal & 37.4 & $37.2-37.6$ & reference & & \\
\hline
\end{tabular}

would be detected at the screening, that only $44 \%$ of the children needed to continue with a rectal measurement and among these children $83 \%$ would be truly febrile. The forehead and ear temperature measurements were both poor to estimate the exact rectal temperature, with a $95 \%$ limits of agreement from around -1.5 to $+1.2{ }^{\circ} \mathrm{C}$ for the forehead measurements and -1 to $+1{ }^{\circ} \mathrm{C}$ for the ear measurements.

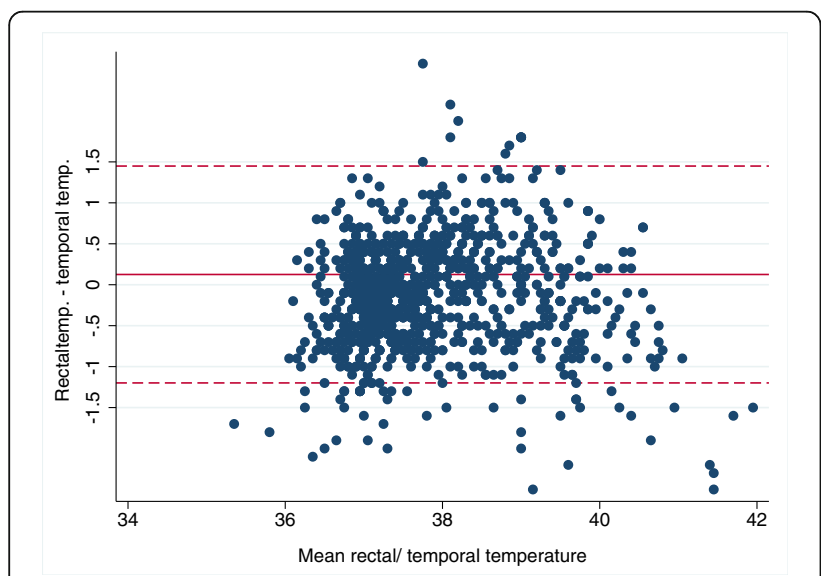

Fig. 2 Bland-Altman plot for temporal and rectal temperatures
The search for alternatives to a rectal measurement of the temperature in children has been going on for decades. Several reviews have reported disappointing results $[2,10,11]$. The instruments used in our study were based on current technologies and developed for professional use. These devices have now been evaluated in a range of studies with mixed results.

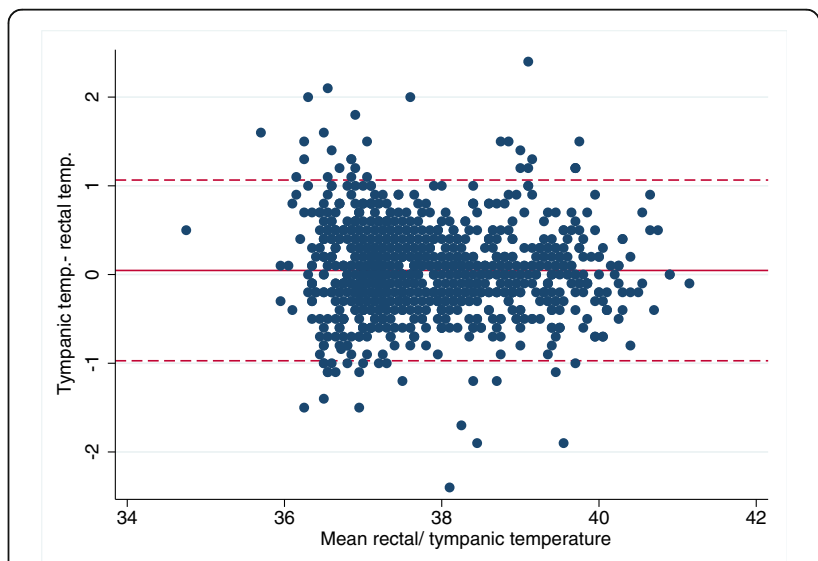

Fig. 3 Bland-Altman plot for tympanic and rectal temperatures 
The temporal device, TAT-5000 IR, was found to be reliable in children in studies from the US of 47 children, India 50 children, and Turkey with 218 children. These studies only found minor temperature differences to the rectal temperature and sensitivities above $80 \%$ to detect fever [4-6].

In contrast, other research groups found that the temporal device was still too inaccurate to be recommended. In Belgium, 294 children had a deviation from the rectal temperature from -1.32 to $+1.33{ }^{\circ} \mathrm{C}$ and the thermometer had sensitivity of $41 \%$ to detect fever [8]. Four studies from the US of 44,52, 147, and 474 children found too large mean differences in temperature and sensitivities from 53 to $70 \%$ to detect fever, [12-15] which are similar to findings among 156 children from Nigeria and 205 children from Argentina [16, 17]. These studies are weakened by small numbers, inadequate statistical methods or no sub-analysis within age groups. Our study does not have these limitations and concludes that temporal measurement is not able to measure the temperature within a clinically safe limits of agreement range nor is it useful as a screening tool for fever.

The infrared ear thermometer, ThermoScan PRO 4000, was examined in a single study of 205 children from Argentina, which also compared it against the same temporal device as in our study: the TAT-5000 IR. The mean temperature difference to rectal temperature was $0.001{ }^{\circ} \mathrm{C}$ and the $95 \%$ limits of agreement from -0.77 to $+0.77{ }^{\circ} \mathrm{C}$. The sensitivity to detect fever was $92 \%$ [17]. These findings are quite similar to our findings. We conclude that the tympanic thermometer is better than the temporal thermometer at measuring temperature but still has a wide limit of agreement range, and almost every tenth child with a fever will go undetected using this method.

These conclusions are valid for the devices used in the study. However, a recent study from Switzerland reached similar results, using other devices which were based on the same technologies [18].

Our findings have a number of clinical implications. Firstly, temporal devices have no place as a substitute or screening tool for temperature measurements. Secondly, the tympanic thermometer has reached a level of accuracy where it can be used as a screening tool for detecting fever, with an AUC of 0.97 and more than $95 \%$ of all children with fever will be detected if the cut point for tympanic measurement is $37.8{ }^{\circ} \mathrm{C}$. It should be considered, however, that there will still be $5 \%$ of the children who are not detected. This means, that an approach of screening all children with the tympanic device and continue with a rectal measurement if the screening is positive would result in that less than half of the children would need a rectal measurement. Thirdly, the usefulness of tympanic temperature to measure the exact temperature is less convincing and the clinicians must accept a limits of agreement range of around $+/-1{ }^{\circ} \mathrm{C}$, which is too wide for clinical use, where a range of less than $+/-0.5{ }^{\circ} \mathrm{C}$ has been considered acceptable [13].

The strength of the current study is that it is a comprehensive real-life pragmatic study with subanalyses in different age groups. Furthermore, in contrast to most of the published studies, it was analyzed with appropriate statistical methods, including BlandAltman analysis [19, 20]. The study is weakened by the fact that the patients were not consecutively included, only when time allowed. Only 39\% had fever, which limits the analysis, even though this is partially compensated by the high number of participants. Since the study was performed anonymously, no comparison was possible between the participating and non-participating children to assess selection bias. Furthermore, the order of temperature measurements was the same throughout the study: temporal, tympanic and rectal. We did so to reduce the risk of crying which could influence the temporal measurements. The procedure might introduce a bias however, if the temperature lowered during the examination. We tried to avoid this by undressing the child partially and only for a short time after the two other measurements had been performed. Finally, in accordance with the vast majority of other studies, and since our clinical guidelines and everyday clinical practice base on rectal measurements, we chose the rectal temperature as the gold standard to represent the core temperature. It has been questioned whether the rectal temperature represents the true core temperature better than the tympanic temperature [1]. Our study design does not address this question, instead merely examining whether the alternatives could replace the well-established rectal method.

The examined ear device is useful for screening purposes, but there is still room for improvement. We encourage the continued search for and development of new methods and technologies to replace the inconvenience of the rectal thermometer. For each new device developed, it is crucial to evaluate the accuracy in a clinical setting by using sufficient numbers of patients and appropriate methods for comparison.

\section{Conclusion}

Based on a large sample of children, we found that temporal measurements of temperature are not presently recommendable, but tympanic measurement performed by devices using the same technology as in this study is useful for screening purposes, especially among children aged 6 months to 5 years. For exact measurements of temperature, we still recommend the rectal method. 


\section{Additional file}

Additional file 1: Sample size calculation. (PDF 448 kb)

Acknowledgements

Not applicable.

\section{Funding}

The project was done with no specific support

\section{Availability of data and materials}

The datasets used and/or analysed during the current study available from the corresponding author on reasonable request.

\section{Authors' contributions}

CBM reviewed the literature, carried out the statistical analysis, revised the manuscript and approved the final manuscript as submitted. LW conceptualized and designed the study, designed the data collection instrument, coordinated and supervised data collection, critically reviewed the manuscript, and approved the final manuscript as submitted. GF reviewed the literature, critically reviewed the manuscript, and approved the final manuscript as submitted. SH assisted in the analysis of the data, drafted the first manuscript, critically reviewed the revised manuscript. All authors read and approved the final manuscript.

\section{Authors' information}

None.

\section{Ethics approval and consent to participate}

In accordance with Danish legislation (Bekendtgørelse af lov om videnskabsetisk behandling af sundhedsvidenskabelige forskningsprojekter) this study was considered a quality assurance study of implemented, recognized technologies with no need of ethical approval. https:// komite.regionsyddanmark.dk/wm428123

All parents consented verbally for the inclusion of all participants in this research

\section{Consent for publication}

Not applicable.

\section{Competing interests}

The authors declare that they have no competing interests.

\section{Publisher's Note}

Springer Nature remains neutral with regard to jurisdictional claims in published maps and institutional affiliations.

\section{Author details}

'University of Southern Denmark, Institute for Regional Health Research, Kresten Philipsensvej 15, 6200 Aabenraa, Denmark. ${ }^{2}$ Pediatric Department Hospital of Southern Denmark, Aabenraa, Denmark.

Received: 11 November 2016 Accepted: 18 January 2018

Published online: 26 January 2018

\section{References}

1. El-Radhi AS. Determining fever in children: the search for an ideal thermometer. Br J Nurs (Mark Allen Publishing. 2014:23(2):91-4.

2. Niven DJ, Gaudet JE, Laupland KB, Mrklas KJ, Roberts DJ, Stelfox HT. Accuracy of peripheral thermometers for estimating temperature: a systematic review and meta-analysis. Ann Intern Med. 2015;163(10):768-77.

3. Hurwitz B, Brown J, Altmiller G. Improving pediatric temperature measurement in the ED. Am J Nurs. 2015;115(9):48-55.

4. Bahorski J, Repasky T, Ranner D, Fields A, Jackson M, Moultry L, Pierce K, Sandell M. Temperature measurement in pediatrics: a comparison of the rectal method versus the temporal artery method. J Pediatr Nurs. 2012;27(3): 243-7.

5. Batra P, Goyal S. Comparison of rectal, axillary, tympanic, and temporal artery thermometry in the pediatric emergency room. Pediatr Emerg Care. 2013;29(1):63-6.
6. Isler A, Aydin R, Tutar Guven S, Gunay S. Comparison of temporal artery to mercury and digital temperature measurement in pediatrics. Int Emerg Nurs. 2014;22(3):165-8

7. El-Radhi AS. Infrared thermometers for assessing fever in children: the ThermoScan PRO 4000 ear thermometer is more reliable than the temporal scanner TAT-500. Evid Based Nurs. 2014;17(4):115.

8. Allegaert K, Casteels K, van Gorp I, Bogaert G. Tympanic, infrared skin, and temporal artery scan thermometers compared with rectal measurement in children: a real-life assessment. Curr Ther Res Clin Exp. 2014;76:34-8.

9. Haugan B, Langerud AK, Kalvoy H, Froslie KF, Riise E, Kapstad H. Can we trust the new generation of infrared tympanic thermometers in clinical practice? J Clin Nurs. 2013;22(5-6):698-709.

10. Siberry GK, Diener-West M, Schappell E, Karron RA. Comparison of temple temperatures with rectal temperatures in children under two years of age. Clin Pediatr. 2002:41(6):405-14.

11. Dodd SR, Lancaster GA, Craig JV, Smyth RL, Williamson PR. In a systematic review, infrared ear thermometry for fever diagnosis in children finds poor sensitivity. J Clin Epidemiol. 2006;59(4):354-7.

12. Hebbar K, Fortenberry JD, Rogers K, Merritt R, Easley K. Comparison of temporal artery thermometer to standard temperature measurements in pediatric intensive care unit patients. Pediatr Crit Care Med. 2005;6(5): 557-61.

13. Reynolds M, Bonham L, Gueck M, Hammond K, Lowery J, Redel C, Rodriguez C, Smith S, Stanton A, Sukosd S, et al. Are temporal artery temperatures accurate enough to replace rectal temperature measurement in pediatric ED patients? J Emerg Nurs. 2014:40(1):46-50.

14. Hoffman RJ, Etwaru K, Dreisinger N, Khokhar A, Husk G. Comparison of temporal artery thermometry and rectal thermometry in febrile pediatric emergency department patients. Pediatr Emerg Care. 2013;29(3):301-4.

15. Holzhauer JK, Reith V, Sawin KJ, Yen K. Evaluation of temporal artery thermometry in children 3-36 months old. J Spec Pediatr Nurs. 2009;14(4): 239-44.

16. Odinaka KK, Edelu BO, Nwolisa CE, Amamilo IB, Okolo SN. Temporal artery thermometry in children younger than 5 years: a comparison with rectal thermometry. Pediatr Emerg Care. 2014;30(12):867-70.

17. Hamilton PA, Marcos LS, Secic M. Performance of infrared ear and forehead thermometers: a comparative study in 205 febrile and afebrile children. J Clin Nurs. 2013;22(17-18):2509-18.

18. Teller J, Ragazzi M, Simonetti GD, Lava SA. Accuracy of tympanic and forehead thermometers in private paediatric practice. Acta Paediatr (Oslo, Norway: 1992). 2014;103(2):e80-3.

19. Bland JM, Altman DG. Statistical methods for assessing agreement between two methods of clinical measurement. Lancet (London, England). 1986; 1(8476):307-10.

20. Hanneman SK. Design, analysis, and interpretation of method-comparison studies. AACN Adv Crit Care. 2008;19(2):223-34.

\section{Submit your next manuscript to BioMed Central and we will help you at every step:}

- We accept pre-submission inquiries

- Our selector tool helps you to find the most relevant journal

- We provide round the clock customer support

- Convenient online submission

- Thorough peer review

- Inclusion in PubMed and all major indexing services

- Maximum visibility for your research

Submit your manuscript at www.biomedcentral.com/submit
Biomed Central 